Results: Seventy-seven patients were included, 58 (75.3\%) were females; the mean age was $54.24 \pm 11.0$ years and seropositivity was founded in $65(84.4 \%)$ for anti-citrullinated protein antibodies and in $58(75.3 \%)$ for rheumatoid factor. The first bDMARD most commonly prescribed were etanercept $(28.6 \%)$ and rituximab (26\%). Regarding the vitamin D status at baseline, the mean serum level for $25(\mathrm{OH})$ vitamin $\mathrm{D}$ was $28.35 \pm 18.21 \mathrm{ng} / \mathrm{mL}$, with the majority of patients having vitamin $D$ insufficiency $(25(\mathrm{OH})$ vitamin $\mathrm{D}<30 \mathrm{ng} / \mathrm{mL})(63.6 \%)$. After 6 months of treatment with the first bDMARD, disease activity measures showed that remission or low activity were achieved in $29.9 \%$ of the patients, using DAS28 criteria; in $42.9 \%$ and $46.8 \%$, according CDAI and SDAI criteria, respectively. Vitamin D serum levels at 6 months were $26.81 \pm 11.72$, with the majority of patients still with vitamin D insufficiency $(62.3 \%)$.

At baseline, patients with vitamin D insufficiency had greater patient VAS (79.00 $\pm 19,14$ vs $71.71 \pm 21.95)$, greater erythrocyte sedimentation rate (ESR) (40.67 \pm 23.17 vs $32.46 \pm 26.09$ ) and greater Health Assessment Questionnaire (HAQ) score $(1.75 \pm 0.609$ VS $1.61 \pm 0.659)$ with neither of them having statistical significance. However, when comparing CRP levels at 6 months, it achieved statistical significance with the Mann-Whitney U-test ( $1.05 \pm 1.79$ VS $1.41 \pm 5.22 ; p=0.026)$. The same tendency was confirmed when analyzing vitamin D levels at 6 months. Patients with vitamin D insufficiency presented greater patient VAS (55.33 \pm 28.82 vs $42.86 \pm 28.28)$, greater ESR $(26.19 \pm 21.57$ vs $21.00 \pm 20.38)$ and greater HAQ score $(1.35 \pm 0.662$ VS $1.34 \pm 0.705)$, although without statistical significance. However, it did achieve statistical significance when comparing baseline DAS28 and HAQ $(5.60 \pm 0.91$ VS $5.38 \pm 1.31 ; p=0.013$ and $1.76 \pm 0.53$ VS $1.59 \pm 0.75 ; p=0.007$, respectively).

Conclusion: Our data failed to demonstrate a statistically significant association between vitamin $D$ serum levels at baseline and at 6 months with disease activity in our RA sample. However, it revealed a positive trend of vitamin D insufficiency related to higher activity disease. Interestingly, it showed that vitamin $D$ insufficiency after 6 months of bDMARD treatment is related to higher DAS28 and $\mathrm{HAQ}$ at baseline. Nonetheless, we insist it is of paramount importance to conduct larger studies to confirm these findings.

REFERENCES:

[1] Bellan M, Sainaghi PP, Pirisi M. Role of Vitamin D in Rheumatoid Arthritis.

Adv Exp Med Biol. 2017;996:155-168.

Disclosure of Interests: None declared

DOI: 10.1136/annrheumdis-2021-eular.4061

\section{POS0503 THE DISCORDANCE BETWEEN PATIENT-REPORTED AND CLINICAL/BIOLOGICAL OUTCOMES COULD HELP IN PREDICTING FUTURE DISEASE IMPACT IN PATIENTS WITH RHEUMATOID ARTHRITIS}

S. Pazmino ${ }^{1}$, A. Lovik ${ }^{2}$, A. Boonen ${ }^{3,4}$, D. De Cock' ${ }^{1}$, V. Stouten ${ }^{1}$, D. Bertrand ${ }^{1}$, M. Doumen ${ }^{1}$, J. Joly ${ }^{5}$, R. Westhovens ${ }^{1,5}$, P. Verschueren ${ }^{1,5}$ on behalf of CareRA study group. ${ }^{1}$ Katholieke Universiteit Leuven, Skeletal Biology and Engineering Research Centre, Department of Development and Regeneration, Leuven, Belgium; ${ }^{2}$ Katholieke Universiteit Leuven, I-Biostat, Leuven, Belgium; ${ }^{3}$ Academic Hospital Maastricht, Department of Internal Medicine, Division of Rheumatology, Maastricht, Netherlands; ${ }^{4}$ Maastricht University, Care and Public Health Research Institute (CAPHRI), Maastricht, Netherlands; ${ }^{5}$ UZ Gasthuisberg Campus, Department of Rheumatology, Leuven, Belgium

Background: Treatment of Rheumatoid Arthritis (RA) has improved significantly based on early treat-to-target (T2T) strategies. Still, decreased health related quality of life (QoL), restricted ability to work and other unmet needs are reported by RA patients even in the absence of disease activity. We previously identified 3 factors representing the broader impact of RA using exploratory factor analysis: a patient-reported factor (patients global health, pain, fatigue and HAQ), a clinical factor (physician's global health, tender and swollen joint count), and a laboratory factor (ESR and CRP) ${ }^{1}$.

Objectives: To test whether the discordance between patient-reported (PRF) and clinical(CF)/laboratory(LF) measures can predict QoL, or has a mediating effect in predicting future disease burden based on disease activity (DAS28CRP). Methods: This is a post-hoc analysis of the 2-year CareRA trial. PRF, CF and LF scores were calculated as weighted (by factor loading) sum of their components at week 16, 52 and 104 after treatment initiation. A discordance score (DS) between PRF and the mean of the other two scores was also computed. Mediation analyses were fitted to test the hypothesis (Figure 1) that DS could be a mediator for predicting PRF, CF and LF at a future time point (week 16, 52 and 104) using DAS28CRP at a previous time point (baseline and week 16). Confidence intervals were estimated via 10000 bootstraps. Finally, a linear regression was fitted for DS to predict future QoL (RAQoL questionnaire; range 0-30; higher values indicating worse QoL).

Results: Patients with early RA ( $n=379$ ) were included with a mean (SD) age of 53.9 (13.0), $77 \%$ seropositive and $69 \%$ women.
The DS was shown to be mediating the effect of DAS28CRP on any future PRF (Table1). On the other hand, there was no mediation effect of the DS in the prediction of the $\mathrm{CF}$ and an inconsistent mediation effect when predicting the LF Moreover, the DS at week 16 significantly predicted $(\mathrm{p}<0.0001)$ RAQoL scores at year 1 with an effect of $\beta 19.05$ (SE 1.58) and an $R^{2}$ of 0.30 (Cl 0.22-0.38). Similarly, it predicted RAQoL $(\mathrm{p}<0.0001)$ at year 2 with a $\beta 19.74$ (SE 1.56) and $R^{2}$ of $0.32(\mathrm{Cl} 0.24-0.40)$.

Figure 1: Postulated mediational path model

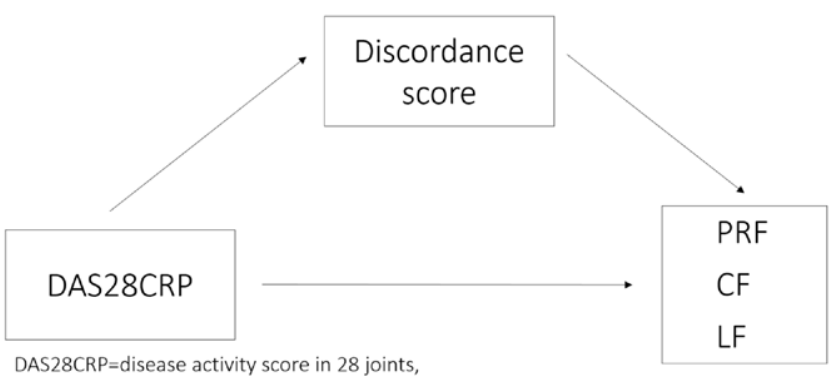

$\mathrm{PRF}=$ Patient reported factor, $\mathrm{CF}=\mathrm{Clinical}$ factor, $\mathrm{LF}=$ Laboratory facto

Table 1. Results of mediation analyses for prediction of future burden based on previous DAS28CRP and mediated by discordance.

\begin{tabular}{|c|c|c|c|c|c|}
\hline Timepoint & $\begin{array}{l}\text { Predictor } \\
\text { variables }\end{array}$ & $\begin{array}{l}\text { Direct } \\
\text { Effect }\end{array}$ & $95 \% \mathrm{Cls}$ & $\mathbf{R}^{2}$ & $\begin{array}{c}\text { Mediation } \\
\text { effect }\end{array}$ \\
\hline \multicolumn{6}{|c|}{ Patient-reported factor } \\
\hline \multirow[t]{2}{*}{ W16 } & DAS28CRP at BL & -0.0091 & $-0.0240,0.0058$ & 0.1450 & Present \\
\hline & $\mathrm{DS}$ at $\mathrm{BL}$ & $0.0246^{*}$ & $0.0169,0.0331$ & 0.1784 & \\
\hline \multirow[t]{2}{*}{ W52 } & DAS28CRP at W16 & $0.0215^{\star}$ & $0.0010,0.0419$ & 0.3394 & Partial \\
\hline & DS at W16 & $0.0580^{\star}$ & $0.0442,0.0739$ & 0.2749 & \\
\hline \multirow[t]{2}{*}{ W104 } & DAS28CRP at W16 & 0.0101 & $-0.0102,0.0305$ & 0.2798 & Present \\
\hline & DS at W16 & $0.0528^{*}$ & $0.0396,0.0686$ & 0.2749 & \\
\hline \multicolumn{6}{|c|}{ Clinical factor } \\
\hline \multirow[t]{2}{*}{ W16 } & DAS28CRP at BL & $0.0153^{\star}$ & $0.0074,0.0232$ & 0.0599 & Absent \\
\hline & $\mathrm{DS}$ at $\mathrm{BL}$ & 0.0019 & $-0.0010,0.0048$ & 0.1784 & \\
\hline \multirow[t]{2}{*}{ W52 } & DAS28CRP at W16 & $0.0365^{\star}$ & $0.0267,0.0463$ & 0.1944 & Absent \\
\hline & DS at W16 & 0.0034 & $-0.0031,0.0095$ & 0.2749 & \\
\hline \multirow[t]{2}{*}{ W104 } & DAS28CRP at W16 & $0.0115^{\star}$ & $0.0024,0.0207$ & 0.0409 & Absent \\
\hline & DS at W16 & 0.0033 & $-0.0019,0.0089$ & 0.2749 & \\
\hline \multicolumn{6}{|c|}{ Laboratory factor } \\
\hline \multirow[t]{2}{*}{ W16 } & DAS28CRP at BL & $0.0063^{*}$ & $0.0015,0.0111$ & 0.0634 & Partial \\
\hline & $\mathrm{DS}$ at $\mathrm{BL}$ & $0.0030^{*}$ & $0.0012,0.0050$ & 0.1784 & \\
\hline \multirow[t]{2}{*}{ W52 } & DAS28CRP at W16 & 0.0003 & $-0.0063,0.0068$ & 0.0305 & Present \\
\hline & DS at W16 & $0.0051^{\star}$ & $0.0012,0.0096$ & 0.2749 & \\
\hline \multirow[t]{2}{*}{ W104 } & DAS28CRP at W16 & -0.0007 & $-0.0079,0.0064$ & 0.0014 & Absent \\
\hline & DS at W16 & 0.0013 & $-0.0019,0.0046$ & 0.2749 & \\
\hline
\end{tabular}

W: week BL: baseline DS: discordance scoreDAS28CRP: disease activity score in 28 joints with C-reactive protein* $\mathrm{p}<0.01$

Conclusion: Early discordance between patient-reported and biological/clinical factors mediates the effect of disease activity on future patient-reported outcomes, but also predicts QoL. Paying attention to this early discordance migh provide opportunities to prevent patient's unmet needs by additional non-pharmacological interventions, hence broadening the scope of T2T.

REFERENCES:

[1] Pazmino S, et al. Does Including Pain, Fatigue, and Physical Function When Assessing Patients with Early Rheumatoid Arthritis Provide a Comprehensive Picture of Disease Burden? J Rheumatol. 2020 Nov 15:jrheum.200758. doi: 10.3899/jrheum.200758. Ahead of print.

Disclosure of Interests: None declared

DOI: 10.1136/annrheumdis-2021-eular.4099

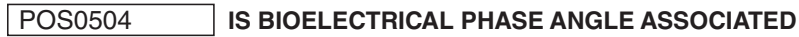 WITH FUNCTIONAL STATUS AND DISEASE IMPACT IN PATIENTS WITH RHEUMATOID ARTHRITIS?}

M. Ferro ${ }^{1}$, S. Charneca ${ }^{1}$, J. Vasques ${ }^{1}$, E. Dourado ${ }^{2,3}$, C. Sousa Guerreiro ${ }^{1,4}$, J. E. Fonseca ${ }^{2,3}$. Laboratório de Nutrição, Faculdade de Medicina, Universidade de Lisboa, Lisbon, Portugal; ${ }^{2}$ Serviço de Reumatologia e Doenças Ósseas Metabólicas, Hospital de Santa Maria, Centro Hospitalar Universitário Lisboa Norte, Centro Académico de Medicina de Lisboa (CAML), Lisbon, Portugal;

${ }^{3}$ Unidade de Investigação em Reumatologia, Instituto de Medicina Molecular, Faculdade de Medicina, Universidade de Lisboa, CAML, Lisbon, Portugal; ${ }^{4}$ Instituto de Saúde Ambiental, Faculdade de Medicina, Universidade de Lisboa, Lisbon, Portugal 